\title{
IODINE STUDIES
}

\section{The Avidity of the Thyrom Gland for Various Iodine COMPOUNDS IN VITRO}

By I. M. RABINOWITCH

With the ASSISTANCE OF ALTHEA B. FRITH

(From the Department of Metabolism, Montreal General Hospital, Montreal, Canada)

(Received for publication, February 9, 1925)

\section{INTRODUCTION}

The literature on the relation of iodine to the thyroid gland is extensive, and a comprehensive review of it is not presented in this paper. Excellent reviews exist. The older literature has been reviewed by Horsley (1), the more recent by Wells (2), Marine (3) and Rost (4). Reference will be made only to those observations relevant to the particular problem under consideration.

It is now generally recognized that though the thyroid gland contains little or no iodine in utero (5), after birth it becomes the chief storehouse for this element. In the adult it contains approximately $2 \mathrm{mgm}$. per gram of dry substance (6). The quantity is much less during the first ten years of life and there appears to be no significant variations due to the sex of the individual (7). It is characterized by a marked disproportion between its importance in the human economy and the amount required for its functional purpose. An intake of approximately $500 \mathrm{mgm}$. a year suffices. With the exception of a minute portion which is in inorganic form or in combination with lipoids (8), all exists in organic form. Practically all of it is found in the "colloid" substance (9) of the thyroid gland, the cells containing negligible quantities. All the iodine may be dissolved out from the thyroid in physiological salt solution (10). Since Baumann's discovery, in 1896, that the chief active ingredient of the colloid is an iodine containing compound, very little has been advanced as to the various chemical compositions in which iodine may exist in the gland, with the exception of the identification of thyroxin (11). 
Great confusion is found regarding the iodine content of the thyroid in disease. It has been frequently found that the iodine content has varied inversely with the degree of epithelial hyperplasia (12) (10) (13). Epithelial hyperplasia is usually regarded as evidence of activity. According to an equal number of observers, thyroid activity was found to vary directly as the iodine content (14). The problem of the relation between the incidence of goiter and the availability of iodine shows still greater confusion. Good clinical results following iodine administration have been observed for many years. Since Baumann's observations that glands in goitrous districts contain less iodine, not only per gram but per gland, the concensus of opinion appears to be that lack of iodine is the causative factor in the production of goiter. In spite of this, however, iodine deficiency cannot be accepted as the only factor. Not only has there frequently been found a normal amount or even an abundance of iodine in goiters, but many well controlled experiments have been reported, which fail to support the view that lack of iodine is the sole cause of goiter (15). Here again clinical experience is corroborative. No satisfactory explanation has yet been offered for success and failure of the same therapy, in two individuals presenting the same clinical picture. Though iodine therapy is successful in the majority of cases of endemic goiter, toxic symptoms have been noted to occur in individuals with apparently the same type of goiter, especially in the case of those living in non-goitrous districts. It has been suggested that iodine may also be useful in toxic goiters, yet it is used as a differential diagnostic test in this condition, because it has been found to intensify the symptoms of toxic goiter (16). Administration of iodine to cases of exophthalmic goiter is known to yield beneficial results. In the majority of instances, however, these are only temporary, and subsequently, by prolonged use, the symptoms may be intensified.

Since the thyroid gland is of such paramount importance in controlling metabolism, and since it appears to require iodine for this function, the selective deposition of this element in the gland is a subject worthy of study. Nagel and Roos (17) first demonstrated that following the administration of iodine to patients, the thyreoglobulin becomes rich in iodine, organically bound. Mendel (18) 
has shown that when the thyroid has little iodine, administration of the latter leads to enormous storage in the gland. The amount may be so great as to produce an acute thyroiditis. Kocher (19) has demonstrated that when iodine is given to a goitrous individual, the concentration of this element in the colloid is increased. Later Marine (2) demonstrated the rate at which iodine may be stored within the gland when fed to animals. Within five minutes after the injection of $50 \mathrm{mgm}$. of potassium iodide into the femoral vein, the concentration may increase several hundred per cent.

Marine (2) first noted that there was a latent period of about 24 hours after iodine administration before a reaction was observed. Boothby and his coworkers (21) later demonstrated such a latent period in the case of thyroxin. The writer (25) in a study of the action of thyroxin, suggested a possible explanation of this phenomenon. Kocher (20) first made the observation that the avidity of the thyroid for iodine may be a function of the concentration of that element already present in the gland. The tissue of an adenomatous thyroid gland does not take up the iodine in the same manner as does the normal thyroid tissue. The importance of this observation appears to have been overlooked, but it has an important bearing on the work to be presented in this paper.

\section{OBSERVATIONS}

Observations have been made upon the following points:

1. The effect of exposure of various tissues to a watery solution of iodine, including muscle, serum, spleen, pancreas, kidney and normal thyroid glands.

2. The effect of exposure of diseased glands to the same solution

3 . The effect on various tissues and diseased thyroid glands of dilute solutions of:

a. Lugol's iodine.

$b$. Acid iodide (made of hydriodic acid and iodine).

c. Potassium iodide.

4. Effect of treating glands exposed as above with chloroform. Regarding the solutions used it may be said that when iodine is dissolved in hydriodic acid or in a solution of potassium iodide, there is evidence of chemical combination with the formation of poly- 
iodides (additive combinations). ${ }^{1}$ Thus $\mathrm{HI}+\mathrm{I}_{2} \rightleftarrows \mathrm{HI} . \mathrm{I}_{2}$ or $\mathrm{HI}_{3}$. The nature of the polyiodides depends upon whether iodine solution has been saturated with iodide or whether the iodide solution has been saturated with iodine. In the former case the lowest, and in the latter the highest polyiodides, are obtained. Thus, though Lugol's solution, and the acid iodide are made of iodine and iodide, it is obvious that the four solutions used in this investigation differ from each other chemically and physically.

\section{TECHNIQUE}

The tissues were first cut up finely and desiccated in an oven at $110^{\circ} \mathrm{C}$. to a constant weight. They were then pulverized in a mortar and passed through a gauze sieve. Any gross particles of fibrous tissue were thus separated. An approximately equal portion (about $1 \mathrm{gram}$ ) was then exposed overnight to the various iodine solutions. Each flask contained approximately $500 \mathrm{cc}$. of an 0.020 per cent solution of total iodine. This concentration was chosen for the purpose of uniformity, since it is approximately the maximum concentration possible in the case of a watery solution of crystalline iodine. The following day the supernatant fluid was decanted and the tissue washed repeatedly with distilled water until the wash water was clear. The tissues were then again dried at $110^{\circ} \mathrm{C}$. to a constant weight. Each specimen was then divided, approximately, into two equal portions. The iodine content was then determined in a known quantity of one portion. The other portion was kept for chloroform treatment. which consisted in the exposure to chloroform overnight. The following day it was washed repeatedly with chloroform, dried to a constant weight and the iodine content determined.

The method of iodine determination was essentially the same as that described by Rabourdin (22), and subsequently employed by Baumann and Roos (23) and Marine and Williams (24), except that colour comparisons were made with the use of a Duboscq colorimeter, and the standard was made by dissolving resublimed iodine in chloroform. In detail it is as follows:

To a known quantity of the tissue (about 0.5 to $1 \mathrm{gram}$ ) in a nickel crucible, 10 cc. of a 20 per cent solution of $\mathrm{KOH}$ are added, and allowed to remain in an oven at $110^{\circ} \mathrm{C}$. for about 30 minutes. The uniform mixture is then evaporated slowly to dryness, avoiding any spurting. This is then carbonized. Potassium nitrate is then added to the carbonized mass and the mixture is heated until a clear flux is obtained. The latter is dissolved in hot water, cooled and quantitatively washed into a $500 \mathrm{cc}$. volumetric flask. It is preferable to filter the solution into the flask.

${ }^{1}$ The results of a comparative study of the clinical use of Lugol's iodine and other polyiodides for exophthalmic goiter in this Hospital, will shortly be published. 
If the latter procedure is adopted, the filter must be repeatedly washed until all iodides have been washed down. To this solution is then added 10 to $25 \mathrm{cc}$. of chloroform, depending upon the nature of the tissue (normal or pathological). Three cubic centimeters of concentrated sulphuric and $2 \mathrm{cc}$. of concentrated nitric acid are then added, and the flask is rapidly rotated. As the iodine is liberated is dissolves in the chloroform, yielding the characteristic color. The long neck of the flask prevents the loss of material due to spurting during the reaction as the acid is added, and during rotation, and facilitates the collection of the chloroform solution. When all the iodine has been dissolved in the chloroform, the flask is. stoppered and inverted. The solution of iodine in chloroform is thus collected and a sufficient quantity is allowed to pass through a dry filter into the colorimetric cup. The intensity of colour is then compared with a solution of chloroform in which the concentration of iodine is known. The usual colorimetric calculations are then applied. Thus:

$$
\frac{S}{R} \times \frac{I}{X} \times \frac{d R}{d S} \times \frac{G}{I}=\text { milligrams of iodine per gram of tissue }
$$

where $S$ = reading of standard.

$R=$ reading of unknown.

$X=$ grams of tissue used.

$d R=$ dilution of unknown.

$d S=$ dilution of standard.

$G=$ milligrams of iodine in standard.

By this method it is possible to recover the added iodine within $0.2 \mathrm{mgm}$., an accuracy sufficient for the purpose of this investigation.

\section{RESULTS AND DISCUSSION}

The results of the experiments are given in the accompanying tables. All figures in the tables represent milligrams per gram of dry tissue. In table 1 are recorded the results of the exposure of various tissues of the body to a watery solution of iodine. In table 2 are recorded the results of the exposure of ten diseased glands to the same solution. It will be noted that, in vitro, the thyroid gland has a greater affinity for iodine than the other tissues of the body. A striking difference is noted in the avidity in the case of pathological glands, as compared with the normal. In table 3 are recorded the results of the exposure of the same tissues to the different forms of iodine. In table 4 are recorded the results of the exposure of diseased glands to the different forms of iodine. It will be noted that in any particular case in these tables, the amount of iodine recovered differs 
with the type of iodine solution. In the case of body tissues other than the normal thyroids, the quantities of iodine recovered are very small or negligible. The avidity of the normal thyroid glands for iodine is again noted to be greater than in the case of the other tissues. Table 4 shows strikingly the results in the case of the diseased glands.

TABLE 1

Effect of exposure to watery solution of iodine

\begin{tabular}{c|c|c|l}
\hline Number & Before exposure & After exposure & \multicolumn{1}{|c}{ Tissue } \\
\cline { 1 - 2 } 1 & 0 & $0.46^{*}$ & Muscle \\
2 & 0 & 1.61 & Serum \\
3 & 0 & 1.89 & Spleen \\
4 & 0 & Trace & Pancreas \\
4 & 0 & 1.14 & Kidney \\
6 & 0.45 & 1.20 & Normal thyroid \\
7 & Not determined & 5.00 & Normal thyroid \\
8 & Not determined & 6.20 & Normal thyroid \\
\hline
\end{tabular}

* Milligram per gram dry tissue.

TABLE 2

Effect of exposure of diseased thyroid glands to a watery solution of iodine

\begin{tabular}{c|c|c|c}
\hline Number & Before exposure & After exposure & \multicolumn{1}{|c}{ Tissue } \\
\cline { 2 - 4 } 1 & & $* 12.1^{*}$ & $\mathrm{~S}-23-232$ \\
2 & & 16.0 & $\mathrm{~S}-24-1062$ \\
3 & 0.14 & 20.9 & $\mathrm{~S}-23-39$ \\
4 & 1.20 & 21.8 & $\mathrm{~S}-24-225$ \\
5 & & 55.4 & $\mathrm{~S}-24-63$ \\
6 & & 44.4 & $\mathrm{~S}-24-194$ \\
7 & 0.36 & 18.5 & $\mathrm{~S}-23-119$ \\
8 & 1.10 & 27.5 & $\mathrm{~S}-23-277$ \\
9 & Trace & 29.7 & $\mathrm{~L}-135$ \\
10 & & 41.1 & $\mathrm{~S}-23-194$ \\
\hline
\end{tabular}

* Milligram per gram dry weight.

Here it will be noted that not only is the avidity greater in each case than the normal for any particular solution, but with any one gland differences as much as $60 \mathrm{mgm}$. per gram may be noted, depending on the type of solution to which the latter was exposed.

Two possible explanations of this phenomenon, other than chemical combination, suggested themselves. One was that the iodine was only 
adsorbed. This was based upon the observation that, in certain instances, within 5 to 6 hours after exposure of the thyroid tissue to the solution, the latter would become almost colorless. It might be recalled here that weak solutions were used $(1 \mathrm{cc} .=0.2 \mathrm{mgm}$. I). Another possible explanation was that the iodine united with the

TABLE 3

Effect of exposure of various tissues and normal thyroid glands to different forms of iodine solutions

\begin{tabular}{|c|c|c|c|c|c|}
\hline Tissue & $\begin{array}{l}\text { Acid } \\
\text { iodide }\end{array}$ & $\begin{array}{c}\text { Lugol's } \\
\text { solution }\end{array}$ & $\mid \begin{array}{c}\begin{array}{c}\text { Potassium } \\
\text { iodide }\end{array} \\
\text { int }\end{array}$ & $\begin{array}{l}\text { Watery } \\
\text { iodine }\end{array}$ & $\begin{array}{l}\text { Maximum } \\
\text { variation }\end{array}$ \\
\hline Muscle. & 0 & 0.61 & Trace & 0.46 & 0.61 \\
\hline Serum. . & 1.79 & 1.05 & Trace & 1.61 & 1.79 \\
\hline Spleen...... & 2.62 & Trace & Trace & 1.89 & \\
\hline Pancreas.... & Trace & Trace & Trace & Trace & \\
\hline Kidney......... & 0.37 & 0.40 & Trace & 1.14 & 1.14 \\
\hline Thyroid (normal). & Trace & Trace & Trace & 1.20 & 1.20 \\
\hline Thyroid (normal).. & 3.9 & 3.1 & 2.8 & 5.0 & 2.20 \\
\hline Thyroid (normal).. & 5.4 & 5.8 & 3.0 & 6.2 & 3.20 \\
\hline
\end{tabular}

* Milligram per gram dry weight.

TABLE 4

Effect of exposure of diseased thyroid glands to various forms of iodine solutions

\begin{tabular}{l|c|c|c|c|c}
\hline \multicolumn{1}{c|}{ Tissue } & Acid iodide & $\begin{array}{c}\text { Lugol's } \\
\text { solution }\end{array}$ & $\begin{array}{c}\text { Potassium } \\
\text { iodide }\end{array}$ & Watery iodine & $\begin{array}{c}\text { Maximum } \\
\text { variation }\end{array}$ \\
\cline { 6 - 6 } S-23-232 & $36.6^{*}$ & 43.0 & 49.3 & 12.1 & 37.2 \\
S-24-1062 & 19.7 & 11.0 & 7.7 & 16.0 & 12.0 \\
S-24-225 & 71.8 & 74.8 & 28.2 & 21.8 & 53.0 \\
S-24-194 & 94.6 & 57.5 & 29.6 & 44.4 & 65.0 \\
S-23-39 & 62.4 & 34.4 & 25.0 & 20.9 & 41.5 \\
S-23-277 & 27.9 & 18.9 & 42.2 & 27.5 & 23.3 \\
S-24-999 & 14.0 & 5.2 & 1.8 & 4.4 & 12.2 \\
S-23-119 & 79.2 & 38.0 & 26.5 & 18.5 & 60.7 \\
L-135 & 92.1 & 69.1 & 59.0 & 29.7 & 62.4 \\
Sloan J. & 35.1 & 45.1 & 50.0 & 51.0 & 15.9 \\
\hline
\end{tabular}

* Milligram per gram dry tissue.

lipoids present. The thyroid gland, unlike other glands of internal secretion, has, however, been found to be poor in lipoids (26). However, it appeared reasonable to test these possibilities, by treating the glands, after exposure to iodine, with chloroform, and comparing the iodine content before and after such treatment. If either of these 
explanations was correct, a marked diminution in the iodine content would be expected after the treatment with chloroform. In table 5 are recorded the results of ten such observations. The amount of iodine taken up by the different glands varied from 3 to $99 \mathrm{mgm}$. per gram. No significant change was noted in the iodine content in any case after chloroform. Of the little change noted, there was no relation between the loss of iodine after chloroform treatment, and the amount taken up by the gland. It is obvious, therefore, that this phenomenon cannot be explained readily by adsorption or chemical combination with lipoids.

TABLE 5

Effect of treatment of exposed glands wilh chloroform

\begin{tabular}{c|c|c|c}
\hline Number & Before treatment & After treatment & Difference \\
\cline { 2 - 3 } & $20.9^{*}$ & 20.4 & 0.5 \\
2 & 19.7 & 18.9 & 0.8 \\
3 & 7.7 & 7.1 & 0.6 \\
4 & 16.0 & 15.9 & 0.1 \\
5 & 3.0 & 2.2 & 0.8 \\
6 & 4.2 & 4.2 & 0 \\
7 & 26.0 & 25.9 & 0.1 \\
8 & 55.4 & 53.6 & 1.8 \\
9 & 99.8 & 99.1 & 0.7 \\
10 & 35.2 & 34.4 & 0.8 \\
\hline
\end{tabular}

* Milligram per gram dry weight.

Grateful acknowledgment is due to Dr. L. J. Rhea, Director of the Pathological Department, for the material made available for this work.

\section{BIBLIOGRAPHY}

1. Horsley. Festschrift f. Virchow, Berlin, 1891.

2. Wells. Chemical Pathology. Philadelphia, 1920, 4th ed.

3. Marine. Physiological Reviews, 1922, ii, 521.

4. Rost. Pathological Physiology. 1923.

5. Fenger. Jour. Biol. Chem., 1912, xi, 489; xii, 55.

6. Marine and Lenhart. Arch Int. Med., 1909, iv, 440.

7. Jolin. Festschr. f. O. Hammerstein. Upsala Lakare foren Forh., 1906, xi, suppl.

8. Blum and Grutzner. Zeit. Physiol. Chem., 1914, xci, 400. 
9. Tatum. Proc. Soc. Exp. Biol. and Med., 1919, xvii, 28.

10. Oswald. Virchow's Arch., 1902, clxix, 444.

11. Kendall. Jour. Amer. Med. Ass., 1918, lxxi, 871. Collected papers of Mayo

Clinic, 1915, 1916; Jour. Biol. Chem., 1919, xxxix, 125.

12. Wells. Jour. Amer. Med. Assoc., 1897, xxix, 897.

13. Marine. Arch. Int. Med., 1908, i, 349, 1909, iii, 66.

14. Fonio. Mitt. Grenz. Med. u. Chir. 1911, xxiv, 123. Quoted by Wells (2).

Frey. Mitt. Grenz. Med. u. Chir., 1914, xxviii, 349.

Hunt. Jour. Amer. Med. Assoc., 1907, xlix, 1323, Jour. Pharm. and Exp. Ther., 1910, ii, 15.

15. Kutschera. Munch. Med.Woch., 1913,1x, 393 and 1813; Sitzber. Wien. Akad. 1914, cxxiii, 35.

16. Kimball. Ohio State Med. Jour., 1924, July.

17. Nagel and Roos. Arch f. Anat. u. Physiol., 1902, 297.

18. Mendel. Med. Klinik., 1906, ii, 833.

19. Kocher. Mitt Grenz. Med. u. Chir., 1905, xiv.

20. Marine and Rogoff. Jour. Pharm. and Exp. Ther., 1916, ix, 1.

21. Plummer and Boothby. Amer. Jour. Phys., 1921, lv, 295.

Boothby and Rowntree. Jour. Pharm. and Exp. Ther., 1923, xxii, 99.

22. Rabourdin. Lieb. Ann., lxxvi, 375. Quoted by Marine (13).

23. Baumann and Roos. Zeit. f. Phys. Chem., 1896, xxi, 481.

24. Marine and Williams. Arch. Int. Med., 1908, i, 349.

25. Rabinowitch. Jour. Biol. Chem., 1924, lxii, 245.

26. Fenger. Jour. Biol. Chem., 1916, xxvii, 303. 